\title{
SELEÇÃO DE FUNGOS PRODUTORES DE TANASE EM RESÍDUOS VEGETAIS RICOS EM TANINOS
}

\author{
Screening of tanase producing fungi present in rich tannin vegetable residues
}

\author{
Gabriela Alves Macedo ${ }^{1}$, Luis Katsumi Matsuda 2 , Vania Battestin ${ }^{3}$
}

\begin{abstract}
RESUMO
Tanino acil hidrolase conhecida como tanase (E.C: 3.1.1.20) é uma enzima que hidrolisa ésteres e ligações laterais de taninos hidrolisáveis produzindo glicose e ácido gálico. A tanase é uma enzima extracelular, induzível, produzida por fungos, bactérias e leveduras pela fermentação sólida, líquida ou submersa. A fermentação sólida para a produção desta enzima oferece um grande número de vantagens sobre o método de fermentação submersa e líquida convencional. O meio de produção é simples, utiliza resíduos vegetais de uva, cajú, café ou subprodutos como farelo de trigo, arroz ou aveia, acrescidos de ácido tânico. A aplicação de resíduos é uma forma de utilizar substratos alternativos e solucionar problemas de poluição que possam causar. A tanase tem vasta aplicação na indústria de alimentos, sucos, cervejaria e indústria farmacêutica. Objetivou-se com este trabalho selecionar linhagens fúngicas potencialmente produtoras de tanase em resíduos vegetais ricos em taninos. A primeira etapa da seleção foi realizada utilizando como substrato farelo de trigo suplementado com 0,5\% de ácido tânico. Dentre as 400 linhagens testadas $6,75 \%$ produziram tanase. As linhagens que apresentaram as melhores atividades foram: LAB345G, LAB53G e LAB153G com atividades de 0,$2862 ; 0,2149 ; 0,1848$ U Essas linhagens foram testadas nos resíduos agroindustriais de café e uva acrescentando $0,5 \%$ e $1,5 \%$ de ácido tânico ao meio de fermentação. O melhor resultado foi obtido para o resíduo de café com a linhagem LAB153G apresentando atividade de $0.275 \mathrm{U}$.
\end{abstract}

Termos para indexação: fungos, tanase, resíduos, taninos.

\begin{abstract}
Tannin acyl hydrolase (E.C: 3.1.1.20) or tannase is an enzyme which hydrolyses ester and depside bonds of hydrolysable tannins releasing gallic acid and glucose. Tannase is an extracellular, inducible enzyme, produced by fungi, bacteria and yeast. The tannase is produced by solid-state, liquid surface and submerged fermentation. The solid-state fermentation offers a number of advantages over submerged and liquid conventional fermentation for the enzimes production. The production is simple, using vegetable residues such as coffee wastes, grape, cashew or by-products as wheat bran, rice or oats, to which tannic acid is added. The use of residues is an alternative to solve pollution problems that can be caused by an incorrect environmental disposal. Tannase enzyme has several applications on food, juices and pharmaceutical industries. The objective of this work was to select tannase producing fungi and to study the production of this enzyme in vegetable residues rich in tannin. The first stage of the selection was carried in solid-state fermentation using as substrate wheat bran supplemented with $0.5 \%$ of tannic acid. Among the 400 tested lineages, $6.75 \%$ of the fungi produced the enzyme. The lineages that showed the best activities were LAB345G, LAB53G and LAB 153G, with $0.3862,0.2149$ and $0.1848 \mathrm{U}$ activities values, respectively these lineages were tested in vegetables residues as coffee and grape, adding 0.5 and $1.5 \%$ of tannic acid in the fermentation environment. The best result was obtained using LA153G and coffee residues, with an activity of $0.275 \mathrm{U}$ being observed.
\end{abstract}

Index terms: screening, tannase, residues, tannin.

(Recebido para publicação em 27 de abril de 2004 e aprovado em 7 de julho de 2005)

\section{INTRODUÇÃO}

Tanino acil hidrolase conhecida como tanase (E.C: 3.1.1.20) é uma enzima que hidrolisa ésteres e ligações laterais de taninos hidrolisáveis (BANERJEE et al., 2001). O ácido tânico é um típico tanino hidrolisável, que pode ser hidrolisado por tanase em glicose e ácido gálico (HELBIG, 2000) (Figura 1). A tanase pode ser obtida a partir de fontes vegetal, animal e microbiana. A tanase está presente em muitas plantas ricas em taninos como myrobalan (Terminalia chebula), divi divi (Caesalpinia coriaria), dhawa (Anogeissus latifolia), konnam (Cassia fistula), babul (Acacia arabica) e avarum, principalmente em suas frutas, folhas, galhos e nas cascas (BANERJEE \& KAR, 2000). De fontes animais, TAH pode ser extraída do intestino bovino e das mucosas dos ruminantes. $\mathrm{O}$ meio microbiológico é a fonte mais importante de obtenção da tanase, uma vez que as enzimas produzidas desta forma são mais estáveis do que aquelas obtidas por outros meios.

\footnotetext{
${ }^{1}$ Docente em Ciência de Alimentos Faculdade de Engenharia de Alimentos - Departamento de Ciência de Alimentos - Caixa Postal 6121 - $13083-862$ UNICAMP - Campinas, SP.

${ }^{2}$ Graduando em Engenharia de Alimentos - Iniciação Científica/Unicamp.

${ }^{3}$ Engenheira de Alimentos - Doutoranda em Ciência de Alimentos/Unicamp.
} 


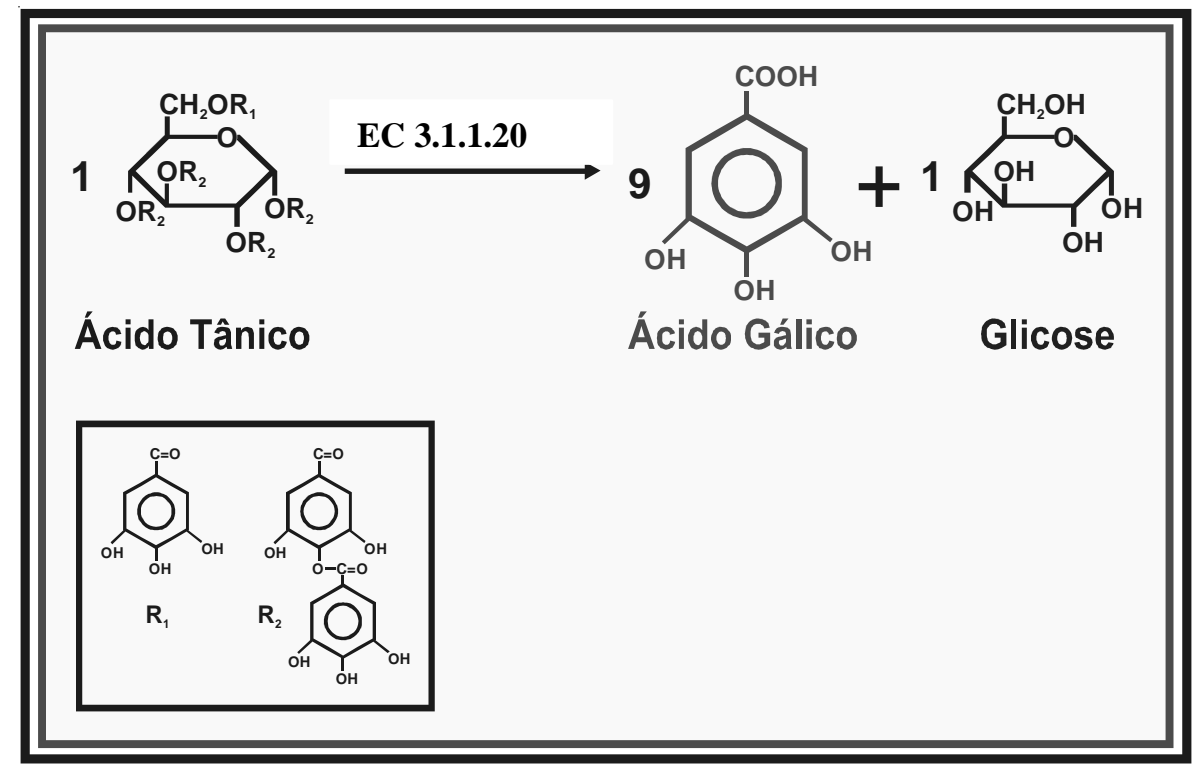

FIGURA 1 - Hidrólise do ácido tânico (AGUILAR et al., 1999).

Além disso, microrganismos podem produzir TAH em altas quantidades e de maneira contínua, com conseqüente aumento de rendimento (BANERJEE et al., 2001).

A tanase é uma enzima extracelular, induzível, produzida na presença de ácido tânico por fungos, bactérias e leveduras (AGUILAR et al., 1999). A primeira etapa para o desenvolvimento do processo de produção de enzimas microbianas é a seleção da linhagem. Enzimas extracelulares são preferidas, pois são mais facilmente extraídas e dispensam métodos de extração mais dispendiosos (COURI et al., 1998). Existem estudos de produção da tanase por fermentação sólida, líquida e submersa (LEKHA \& LONSANE, 1994).

A fermentação sólida para a produção de enzimas oferece vantagens sobre o método de fermentação submersa e líquida convencional (LAGEMAAT \& PYLE, 2001). O meio de produção é simples, pode-se utilizar subprodutos agroindustriais como casca de uva, caju, café ou farelo de trigo, arroz e aveia, acrescidos de ácido tânico. Lekha \& Lonsane (1997) produziam tanase de Aspergillus niger e Penicillium glabrum utilizando farelo de trigo e Aguilar \& Gutiérrez-Sanchez (2001) e Lagemaat \& Pyle (2001) produziram tanase em espuma de poliuretano.

A utilização de resíduos provenientes de indústrias processadoras de frutas e grãos pode consistir em uma alternativa para promover a redução dos custos de produção da enzima e evitar problemas de poluição que possam causar. O interesse na fermentação sólida para a produção de compostos de importância comercial é uma conseqüência da demanda por insumos de menor custo.

Embora existam muitas aplicações industriais da tanase em potencial, poucas são efetivamente empregadas devido essencialmente ao custo de produção da enzima, que ainda é elevado e, principalmente ao pouco conhecimento sobre seu modo de ação catalítica. A enzima pode ter vasta aplicação na indústria de alimentos, principalmente sucos, cervejaria, cosméticos, farmacêutica e indústria química (LEKHA \& LONSANE, 1997), sendo principalmente utilizada para produção de ácido gálico, chás instantâneos, na estabilização da coloração de vinhos, refrigerantes a base de café, processo de tratamento de couro, detanificação de alimentos e para tratamento de efluentes na indústria de couros (BANERJEE et al., 2001). No presente estudo, objetivou-se selecionar linhagens fúngicas produtoras de Tanino Acil Hidrolase, e testar as melhores linhagens em substratos provenientes de resíduos agroindustriais ricos em taninos através de fermentação sólida. 


\section{MATERIALEMÉTODOS}

\section{Microrganismos}

Foram testadas 400 linhagens fúngicas pertencentes ao Laboratório de Bioquímica da Faculdade de Engenharia de Alimentos da UNICAMP.

\section{Preparação do Inóculo}

As linhagens fúngicas foram repicadas em meio inclinado PDA (Potato Dextrose Agar) com suplemento de $0,2 \%(\mathrm{p} / \mathrm{v})$ de ácido tânico $\left(\mathrm{C}_{76} \mathrm{H}_{42} \mathrm{O}_{56}\right)$ e incubadas em estufa Fanem a $30^{\circ} \mathrm{C}$ por 72 horas.

\section{Meio de Fermentação}

Em frascos Erlenmeyers de $250 \mathrm{~mL}$ foram adicionados $10 \mathrm{~g}$ de de farelo de trigo e $10 \mathrm{~mL}$ de solução de sais na composição $(\mathrm{g} / \mathrm{L}): \mathrm{KH}_{2} \mathrm{PO}_{4} 1.0 ; \mathrm{NH}_{4} \mathrm{NO}_{3} 2.0$; $\mathrm{MgSO}_{4} \cdot 7 \mathrm{H}_{2} \mathrm{O}, 0.2 ; \mathrm{CaCl}_{2} \cdot 2 \mathrm{H}_{2} \mathrm{O}, 0.02 ; \mathrm{MnCl}_{2} \cdot 4 \mathrm{H}_{2} \mathrm{O}, 0.004$; $\mathrm{Na}_{2} \mathrm{MoO}_{4} \cdot 2 \mathrm{H}_{2} \mathrm{O}, 0.002 ; \mathrm{FeSO}_{4} \cdot 7 \mathrm{H}_{2} \mathrm{O}, 0.0025$ e ácido tânico, $10(\mathrm{~g} / \mathrm{L})$. O meio de cultivo foi esterilizado a $120^{\circ} \mathrm{C}$ por 20 minutos, com umidade relativa $60 \%$ (BU) e pH 5,7. Após a esterilização os frascos foram inoculados com $5 \times 10^{7}$ esporos $/ \mathrm{mL}$ e incubados a $30^{\circ} \mathrm{C}$ em estufa Fanem por 120 horas (os esporos foram removidos adicionando-se 2,5 $\mathrm{mL}$ de água destilada e raspados com auxilio de alças de inoculação, a contagem dos esporos foi feita em câmara de Neubauer). Após fermentação, foram adicionados $100 \mathrm{~mL}$ de solução $\mathrm{NaCl} 1,5 \%$ e agitados a 200 rpm por 2 horas. A solução foi filtrada e centrifugada a $12.300 \mathrm{~g}$ por 30 minutos a $4^{\circ} \mathrm{C}$, o sobrenadante foi denominado extrato enzimático (LEKHA \& LONSANE, 1997).

\section{Medida da Atividade Enzimática da Tanase}

A solução de substrato foi preparada pela adição de 0,5 \% (p/v) de ácido tânico em tampão acetato pH 5,5 $0,2 \mathrm{M}$. A reação foi realizada adicionando-se $0,3 \mathrm{~mL}$ da solução de substrato com $0,5 \mathrm{~mL}$ de extrato enzimático bruto e incubada a $60^{\circ} \mathrm{C}$ por 10 minutos. Após a incubação, a reação foi paralisada pela adição de $3 \mathrm{~mL}$ de solução de albumina de soro bovino (BSA) preparada na concentração de $1 \mathrm{mg} / \mathrm{mL}$ e $0,17 \mathrm{M}$ de cloreto de sódio em tampão acetato $\mathrm{pH} 5,0,0,2 \mathrm{M}$, e em seguida centrifugada a $12.300 \mathrm{~g}$ por 15 minutos a $4^{\circ} \mathrm{C}$. O precipitado foi ressuspenso em $3 \mathrm{~mL}$ de solução SDS-trietanolamina acrescido de $1 \mathrm{~mL}$ de solução de $\mathrm{FeCl}_{3}$ A absorbância foi medida após 15 minutos em $530 \mathrm{~nm}$ conforme metodologia descrita por Mondal et al. (2001).

A atividade enzimática foi calculada pela diferença da leitura de absorbância medida a $530 \mathrm{~nm}$ entre amostra e tubo controle. Uma unidade de atividade de tanase foi definida como a quantidade de ácido tânico hidrolisado por $\mathrm{mL}$ de enzima empregada por minuto de reação: $A b s_{530}=A b s_{\text {controle }}-A b s_{\text {teste }}$.

As linhagens selecionadas como melhores produtoras potenciais de tanase foram testadas em substratos provenientes de resíduos agroindustriais de indústrias de processamento de polpas e sucos da Região de Campinas-SP.

\section{Extração e quantificação dos taninos}

Resíduos de café, uva, caju, carambola e acerola na forma em pó, sofreram extração com hexano na concentração der $3 \mathrm{~mL} / \mathrm{g}$ de amostra, mediante três lavagens sucessivas. Em seguida, a amostra foi lavada três vezes com etanol (3 $\mathrm{mL} / \mathrm{g}$ de amostra) a $4^{\circ} \mathrm{C}$. O extrato obtido foi centrifugado a $12.300 \mathrm{~g}$ por 15 minutos a $4^{\circ} \mathrm{C}$ e no sobrenadante foram quantificados os taninos. A um volume de $1,0 \mathrm{~mL}$ do extrato etanólico obtido foram adicionados $2,0 \mathrm{~mL}$ de solução padrão de proteínas composta por tripsina, ovoalbumina e albumina de soro bovino $(1,0 \mathrm{mg} / \mathrm{mL})$ em tubos de $15 \mathrm{~mL}$. A mistura foi homogeneizada à temperatura ambiente e após 15 minutos foi centrifugada a $12.300 \mathrm{~g}$ por 15 minutos a $4^{\circ} \mathrm{C}$. O sobrenadante foi descartado e o precipitado ressuspenso em $4 \mathrm{~mL}$ de solução SDS-Trietanolamina. A esta solução foi adicionado $1 \mathrm{~mL} \mathrm{de} \mathrm{FeCl}_{3}$ e após 30 minutos foi medida a absorbância da amostra em $530 \mathrm{~nm}$ seguindo a metodologia de Hagerman \& Butler (1978).

\section{RESULTADOS E DISCUSSÃO}

A seleção de linhagens fúngicas produtoras de tanase foi realizada em meio de fermentação sólida utilizando como substrato farelo de trigo suplementado com $0,5 \%$ de ácido tânico. Entre as 400 linhagens testadas, $87,25 \%$ dos fungos não sintetizaram a enzima, $6,0 \%$ dos fungos foram inibidos na etapa de pré-inoculação quando utilizou-se o meio PDA com 0,2\% (p/v) de ácido tânico, comprovando o efeito de inibição que os taninos podem exercer sobre o crescimento de microrganismos. Em relação às propriedades antimicrobianas dos taninos, muitos fungos, bactérias e leveduras são resistentes aos taninos e podem crescer e se desenvolver na presença destes, como: Aspergillus, Penicillium, Fusarium, Bacillus cereus, Corynebacterium $s p$, Candida $s p$ e Pichia $s p$ (BHAT et al., 1998). Os resultados da seleção indicaram que 6,75\% das linhagens testadas são capazes de sintetizar Tanino acil hidrolase nas condições do teste de atividade da tanase. 
Com o objetivo de selecionar os melhores fungos produtores da tanase, optou-se pela escolha das linhagens com atividade superior ou igual a $0,12 \mathrm{U}$ (Tabela 1 ).

TABELA 1 - Linhagens pré-selecionadas como produtoras de tanase em farelo de trigo com $0,5 \%$ (p/p) de ácido tânico após 120 horas de fermentação.

\begin{tabular}{lc}
\hline Linhagem & $\mathbf{U}(\boldsymbol{\mu m o l} / \mathbf{m i m} . \mathbf{m l}$ enzima $)$ \\
\hline LAB345G & 0,2862 \\
LAB53G & 0,2149 \\
LAB153G & 0,1848 \\
LAB306G & 0,1681 \\
LAB343G & 0,1513 \\
LAB146G & 0,1242 \\
\hline
\end{tabular}

As linhagens com maior potencial produtor de tanase foram as de número LAB345G, LAB53G e LAB153G com valores de atividade de 0,2862, 0,2149 e 0,1848 U, respectivamente. Essas linhagens foram testadas em meio a base de resíduos agroindustriais de café e uva adicionando-se $0,5 \%$ e $1,5 \%$ de ácido tânico ao meio de fermentação. $\mathrm{Na}$ determinação de taninos totais dos resíduos agroindustrias verificou-se que casca de café e uva permitiram a formação de maiores concentrações de taninos dentre os resíduos testados de caju, carambola e acerola, apresentando valores de $0,073 \%$ e $0,941 \%$, respectivamente. A esses resíduos foram adicionados ácido tânico nas concentrações de 0,5 e $1,5 \%(\mathrm{p} / \mathrm{p})$ para os testes de fermentação. Pela Figura 2 verificam-se os resultados obtidos para a fermentação sólida em farelo de trigo, resíduos de café e uva com adição de $0,5 \%$ e $1,5 \%$ (p/p) de ácido tânico.

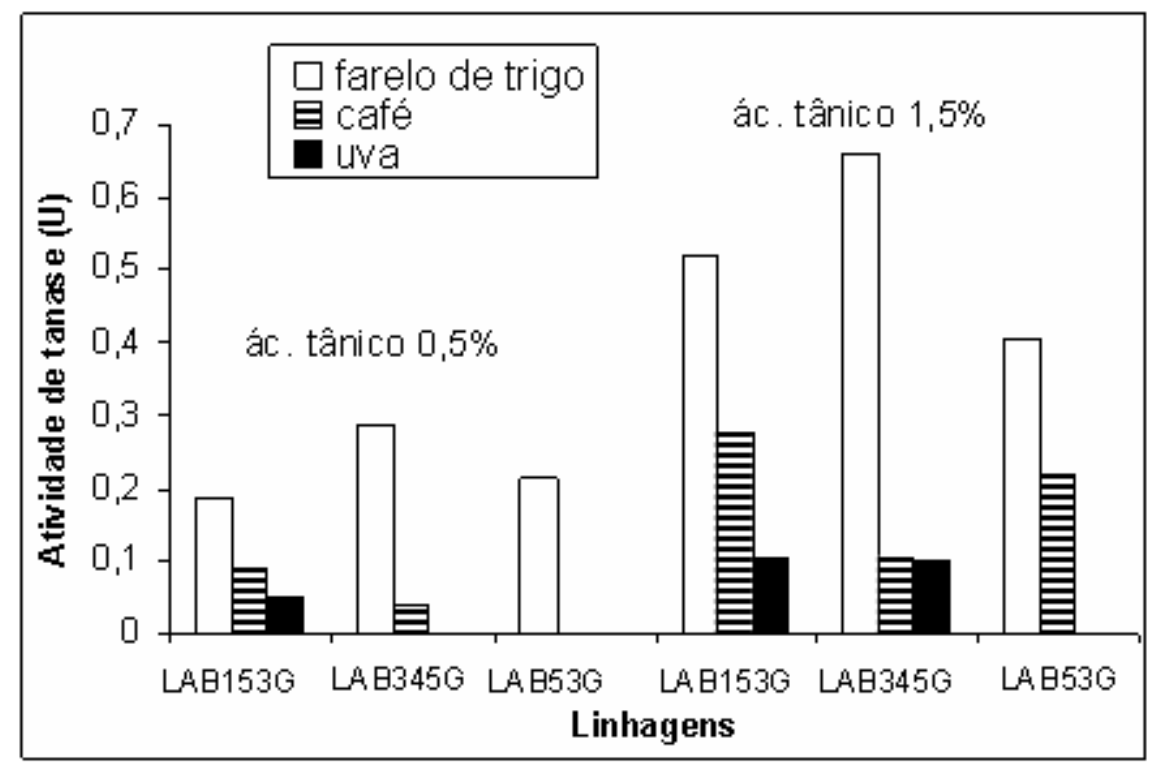

FIGURA 2 - Produção de tanase pelas linhagens LAB153G, LAB345G e LAB53G em farelo de trigo e resíduos de café e uva com $0,5 \%$ e 1,5\% (p/p) de ácido tânico após 120 horas de fermentação. 
O farelo de trigo tem sido até hoje o substrato mais estudado para produção de tanase por fermentação sólida. Todas as linhagens testadas neste resíduo foram capazes de produzir a enzima conforme visto na Figura 2. As linhas LAB153G, LAB345G, LAB53G apresentaram valores de atividade de 0,522, 0,663 e 0,406 U quando se adicionou 1,5\% de ácido tânico, resultando em aumentos de 2,8; 2,3 e 1,9 vezes se comparados à atividade enzimática com $0,5 \%$ de ácido tânico. No resíduo de café, com adição de 1,5\% de ácido tânico, todas as linhagens produziram tanase. Para as linhagens LAB153G e LAB345G aumentando a concentração de ácido tânico de $0,5 \%$ para $1,5 \%$ resultou em acréscimos de 3 e 2,8 vezes na atividade enzimática que passou de 0,089 e 0,038 U para 0,275 e 0,106 U. Para a linhagem LAB53G, a produção somente ocorreu com 1,5\% de ácido tânico com atividade de 0,216 U. Para o resíduo de uva, as linhagens LAB153G e LAB345G produziram tanase com adição de $1,5 \%$ de ácido tânico com atividades de 0,1037 e 0,1021 U. Com adição de 0,5\% de ácido tânico somente a linhagem LAB153G produziu a enzima com $0,0498 \mathrm{U}$.

O resíduo de café mostrou-se promissor substituto do farelo de trigo, com resultados melhores que os obtidos com os resíduos de uva. O teor de tanino total presente nos resíduos agroindústrias não parece ser assimilável ao metabolismo dos microrganismos sendo necessário suplementação. Apesar de o farelo de trigo ser considerado um bom substrato para a produção da tanase, é necessário que se explore outros resíduos que possam ser eficientes em relação à produção da enzima. Para o resíduo de café, quantidades apreciáveis da tanase foram produzidas, portanto, a utilização deste resíduo consiste em uma alternativa viável e de menor custo para produção da tanase em fermentação sólida. Estudos indicam que apenas $6 \%$ do conteúdo de uma cereja de café colhida transformase em bebida. O restante (polpa, casca e mucilagem) é descartado ao longo do processo, produzindo assim uma grande proporção de resíduos e subprodutos, os quais tem que ser reprocessados para a sua utilização (PULGARIN et al., 1991).

A produção da enzima mostrou estar diretamente relacionada com a concentração de ácido tânico que é adicionada ao meio de fermentação. Esta fonte de carbono favorece a produção rápida de tanase que, por sua vez, cliva os taninos fornecendo suprimento contínuo de fonte de carbono. Em estudo realizado por Mondal et al. (2001) quando se utilizou Bacillus cereus KBR9 para a produção da tanase adicionando $10 \mathrm{~g} / 1$ de ácido tânico ao meio de fermentação submersa, obteve-se valores para a atividade enzimática de 0,22 U/mL. De acordo com Bajpai \& Patil (1997), Lekha \& Lonsane (1997) e Pinto (2003), o ácido tânico desempenha o papel de fonte de carbono para o microrganismo, bem como de indutor da síntese. Dessa maneira, a presença de ácido tânico é imprescindível para a síntese de tanase. Em trabalho realizado por Pinto (2003) em experimento preliminar no qual não se adicionou ácido tânico ao meio de fermentação, não foi observada atividade de tanase em nenhum tempo de fermentação.

Serão realizados estudos posteriores para determinação do efeito da concentração de ácido tânico ao meio de fermentação, mas os resultados atuais indicam que a concentração é importante na indução da tanase pelos fungos estudados.

\section{CONCLUSÕES}

Foram obtidas de 400, 27 linhagens potencialmente produtoras de tanase mediante seleção induzida pela presença de ácido tânico.

Demonstrou-se que a concentração de ácido tânico no meio de cultura é fator chave na produção da tanase, sendo objeto de mais estudos em andamento.

Dentre os resíduos analisados, uva e café foram selecionados devido a maior concentração de taninos totais. Nos testes fermentativos, no resíduo de casca de café, foram obtidas as melhores respostas de produção da tanase em relação à uva.

\section{REFERÊNCIAS BIBLIOGRÁFICAS}

AGUILAR, C.;AUGUS, C.; GONZÁLEZ, G.; FAVELA, E.A comparison of methods to determine Tannin Acyl Hydrolase Activity. Brazilian Archives of Biology and Technology, Curitiba, v. 42, n. 3, p. 355-361, 1999.

AGUILAR, C. N.; GUTIÉRREZ-SANCHEZ, G. Review: sources, properties, applications and potential uses of tannin acyl hydrolase. Food Science Technology International, London, v. 7, p. 373-382, 2001.

BAJPAI, B.; PATIL, S. Induction of tannin acyl hidrolase (EC 3.1.1.20) activity in some members of fungi imperfecti. Enzyme and Microbial Technology, [S.1.], v. 20, p. 612-614, 1997.

BANERJEE, D.; KAR, B. Biosynthesis of tannin acyl hydrolase from tannin-rich forest residue under different fermentation conditions. Journal of Industrial Microbiology \& Biotechnology, [S.1.], v. 25, p. 29-38, 2000. 
BANERJEE, D.; MONDAL, K. C.; PATI, B. R. Production and characterization of extracellular and intracellular tannase from newly isolated Aspergillus aculeatus DBF 9. Journal Basic Microbiology, [S.1.], v. 41, p. 313-318, 2001.

BHAT, K. T.; SINGH, B.; SHARMA, P. O. Microbial degradation of tannins: a current perspective. Biodegradation, [S.1.], v. 9, p. 343-357, 1998.

COURI, S.; TERZI, S. C.; SILVA, F. D.; FREITAS, S. P.; PINTO, G. A. S. Seleção de linhagens mutantes de Aspergillus niger, para síntese de enzimas hidrolíticas por fermentação em meio semi-sólido. Ciência e Engenharia, [S.1.], v. 7, n. 2, p. 29-31, 1998.

HAGERMAN, A. E.; BUTLER, L. G. Protein precipitation method for the quantitative determination of tannins. Journal Agricultural Food Chemistry, Easton, v. 26, n. 4, 1978.

HELBIGE. Açãodamaceração prévia ao cozimentodofeijãocomum (Phaseolus vulgaris, $L$ ) nos teores de fitatos e taninos e consequiências sobre o valor protéico. $2000.67 \mathrm{f}$. Dissertação (Mestrado) - Universidade Estadual de Campinas, Campinas, 2000.

LAGEMAAT, J. V.; PYLE. D. L. Slid-state fermentation and bioremediation: development of a continuous process for the production of fungal tannase. Chemical Engineers Journal, [S.1.], v. 84, p. 15-123, 2001.

LEKHA, P. K.; LONSANE, B. K. Comparative titres, location and properties of tannin acyl hydrolase produced by aspergillus niger PKL 104 in solid-state, liquid surface and submerged fermentations. Process Biochemistry, [S.1.], v. 29, p. 497-503, 1994.

LEKHA, P. K.; LONSANE, B. K. Production and application of tannin acyl hidrolase: state of the art. Advances in Applied Biochemistry and Microbiology, [S.1.], v. 44, p. 215-260, 1997.

MONDAL, K. C.; BANERJEE, D.; JANA, M.; PATI, B. R. Colorimetric assay method for determination of the Tannin Acyl Hidrolase activity. Analytics Biochemistry, [S.l.], v. 295, p. 168-171, 2001.

PINTO, G. A. S. Produção de Tanase por Aspergillus niger. 2003. 213 f. Tese (Doutorado) - Universidade Federal do Rio de Janeiro, Rio de Janeiro, 2003.

PULGARIN, C.; SCHWITZGUEBEL, J.P.; TABACCHI, R. Utilization of wastes from coffee production. Lausanne, Biofutur, n. 102, p. 43-50, 1991. 